\title{
In memoriam of the late Professor Colette Marsan (1927-2012)
}

Prof. Colette Marsan was one of the first cytopathologists in France and the best-known contemporary French pathologist in Poland.

Born on July $4^{\text {th }} 1927$ in Paris, she graduated in medicine and chose pathology. Inspired by Prof. Sicard she became interested in the development of cytopathology, which remained her favoured subject for life. Prof. Marsan was especially interested in cytology of the uterine cervix. She began her work at the Lariboisière University Hospital, and from 1977 she was employed at Argenteuil Hospital Centre near Paris. In this institution Prof. Marsan organized the Department of Anatomy and Pathological Cytology, which she chaired until retirement. Colette Marsan was unusually active and creative. Her bibliography consists of about 200 research papers mostly dealing with cytodiagnosis of the uterine cervix, several renowned books and atlases on cytological diagnosis published in French, English and Slovenian. As an authority in cytopathology Prof. Marsan was frequently an invited speaker during congresses and conferences, including in Poland. She was quick to follow new developments in cytology and pathology as an initiator and editor of excellent atlases of cytodiagnosis and materials for self-education on CDROMs (e.g. "Cytotrain" in Leonardo da Vinci Program). Some of those projects were carried out together with international experts. Prof. Marsan was elected President of the French Society of Cytology for several terms, a member of scientific boards of several professional journals, and a member of several scientific societies including the International Academy of Cytology (FIAC).

Prof. Marsan was interested in new trends in pathology. As early as in the 1970s she initiated organization and was a director of a school of techniques used in anatomy and cytopathology (ESTAC) at the Faculty of Medicine Lariboisière - St Luis, Paris VII. She was also engaged in the activities of the French Society for Quality Assurance in Anatomy and Cytopathology (AFAQAP) and the Centre of Teaching Research and Documentation in Cytology (CERDEC). Prof. Marsan shared her knowledge and experience with others. Many residents, physicians, technicians and research fellows from France and abroad visited her department at Argenteuil. Polish pathologists were also among them. Her links with Polish pathologists were truly bonds of friendship. She was the author of several joint research papers, an active participant in the Congresses of the Polish Society of Pathologists, and a member of the Editorial Board of the "Polish Journal of Pathology". She was also a spiritus movens of several important initiatives implementing and improving quality assurance in cervical cytology in Poland. With her help and advice we organized in the Department of Pathology, Pomeranian Medical University in Szczecin, annual courses in cervical cytology for pathologists and medical cytomorphologists, starting from 1999. From the very beginning, for seven consecutive years Prof. Marsan gave lectures during those courses. Prof. Marsan was awarded honorary membership of the Polish Society of Pathologists in appreciation of her contribution to pathology in Poland. Professional collaboration with Prof. Marsan led to a warm and friendly, long-lasting personal relationship. Many warm and friendly meetings in the beautiful apartment of Prof. Marsan and her husband, in the heart of Paris at the Cité, interesting conversations, exciting theatre and concert experiences remain in my memory and in my heart.

Prof. Colette Marsan was an extraordinarily warm person. Elegant and respectable, but at the same time warmhearted, kind and friendly. She was a deeply religious person emanating truly Christian experience of joie de vivre. Prof. Marsan loved classical music and was interested in ancient art and painting. She was fascinated by the beauty of stained-glass windows in the XV century parochial Church of Saint-Severin to such a degree that she inspired and organized the production of a CD-ROM (2004) with beautiful photographs of these windows and their description in three languages. Prof. Marsan devoted much of her time to charity. She was an active member of a society supporting blind people and people with amblyopia (Groupement des Intellectuels Aveugles ou Amblyopes) and she was the editor-in-chief of a bulletin edited in the Braille alphabet for the blind, and on CD.

In the last stage of her diligent and fruitful life, despite an incurable disease, which she accepted with dignity, Colette Marsan was active as far as possible. Surrounded by the great care of her husband, children and grandchildren, Colette Marsan died on April 30 $0^{\text {th }}$ 2012. A requiem mass for her soul was celebrated on May $3^{\text {rd }} 2012$ in her beloved Saint-Severin church in Paris.

Non omnis moriar. Colette Marsan has left behind many friends, grateful students, works and initiatives which will bring fruit in the future.

Maria Chosia 